\title{
Targeted English course for agricultural and environmental engineering students: a tool to increase motivation and competitiveness
}

\author{
Oksana Gagarina ${ }^{1, *}$ \\ ${ }^{1}$ Saint-Petersburg Mining University, 2, 21 liniya, 199106, St Petersburg, Russia
}

\begin{abstract}
Being a lingua franca in science and technology, English is still second-rate among agricultural and environmental engineering students in Russia as they do not consider English to be a profession-related subject. The article addresses an issue of revealing the needs of agricultural and environmental engineering students in language learning and designing a tailored course that integrates English into a range of professional subjects. The main purpose is to make the course better adjusted to the learners' needs. A survey involving 85 agricultural and environmental engineering students and 65 researchers, engineers and lecturers was carried out. The purpose was to identify students' expectations from the course, as well as gather information on professional communication areas where English is used. Professional engineers turned out to struggle with speaking necessary for oral communication and delivery of presentations, as well as writing. The students had low motivation due to lack of practice and unawareness of benefits that English may bring for professional career. The revealed needs were incorporated into the tailored module of English for Specific Purposes. It contained Task-based learning, carefully selected professional and cultural materials. The module proved its effectiveness that resulted in increased motivation of students to learn and use English as they got aware of new prospects that English had to offer.
\end{abstract}

\section{Introduction}

The English language has been playing the role of lingua franca worldwide for a couple of decades now. It has become the language of international professional communication as well. Moreover, English is a compulsory skill in many international corporations. Therefore, it has become more important than ever to equip students with the English language skills they need [1]. The system of education in Russia has always been aware of the importance of language acquisition for specialists-to-be which is why foreign languages have been a part of a curriculum in any technical institution. However, for many years it focused on developing reading skills and translation only. In the 1990s the political situation changed dramatically, Russia became open to the global market. As a result, a great number of international enterprises in various fields started their branches in Russia creating jobs for English-speaking professionals, many other English-related opportunities emerged as well.

*Corresponding author: OYu@ pers.spmi.ru 
English has transformed from an obligatory subject of little practical use into a tool of professional development and successful intercultural communication. Out-of-date language programmes did not meet new requirements, grammar and translation approaches of language acquisition fell behind the times. A lot has been done since that time. Nowadays agricultural and environmental engineering students and language tutors enjoy the availability of information, teaching resources, they have access to various tools facilitating the process of language learning. Resources may even seem overwhelming making the choice of most suitable and useful ones difficult and time-consuming. The issue of needs analysis has therefore become relevant.

The needs of agricultural and environmental engineering students are not a constant value. Science, technology, engineering, mathematics as well as professional environment and standards are developing at a fast pace and therefore the needs should be identified for every group. Moreover, students' priorities and attitudes are changing as well. They see new opportunities and challenges in their major that can be approached with the help of a good command of English [2].

\section{Methods}

English tutors unanimously agree that needs analysis is an essential step for a successful language acquisition. However, some "educators and curriculum designers still prepare syllabuses and curricula without even consulting the clients" [3].

Needs analysis has been among the most important ones since late XX century. A great deal of research has been done into it since that time. As intrinsic motives of second language learners became more diverse, many researchers and practitioners called for thorough analysis of learners' needs $[4,5,6,7]$. Needs analysis is a popular tool in identifying the area of study [8]. It is an essential stage in a design of any English course for Specific Purposes (ESP) [9-15]. The entire course of ESP, its content and objectives are based on the specific needs of target learners [16, 17].

To communicate in a foreign language effectively, it is not enough to know words and grammar rules of general English. Some research suggests that significant numbers of students are challenged by academic discourse [18]. Cultural factors affect the progress and success of communication significantly. In real-life communication we deal with people that have specific cultural background and are used to certain styles of communication which may seem unusual to us. Moreover, some topics can be really sensitive in a number of countries [19-22], which is why it is necessary to focus on the importance of intercultural awareness in context, to show respect for diverse identities [23]. The idea expressed by Edward Sapir that "speech is a non-instinctive, acquired, "cultural" function" is still globally recognized and accepted [24]. Thus, different approaches and content should be integrated in the course of English. The integrated approach is used by many tutors for different purposes. For instance, Belousova and Epritskaya argue that various approaches should be implemented in practice alongside depending on communicative situation and learning needs [25]. Makarova suggests an idea of a peer assisted learning strategy aimed at the development of EFL speaking skills of low-skilled students [26]. Apart from revealing students' needs, it is of great importance to identify the needs of professionals as "a long-term view of the workplace communication needs of business professionals can provide insights for ESP research and practice" [1]. It brings us to the idea that a number of factors should be taken into consideration to reveal the needs of a language learner. In the case of engineering students, we should think about both, personal and professional needs. This is the way to maintain high motivation. When it comes to the course design process, we should try to meet the revealed needs. It is often a challenging task as students often do not have any work experience and their vision of the major is vague. Some research claims that being immersed in a research 
site and forming relationships with practitioners are necessary [27]. To identify the English language needs of engineering students in the area of intercultural communication and meet them, a bunch of procedures are required - deep insight into the professional standards, careful study of the educational standard, needs analysis questionnaire design, thorough development of the language course.

The following methods were used to reveal the needs of the target audience:

\subsection{Study of professional and educational standards}

Knowing the standards in the academic and professional area is important for goal setting and course design. The Ministry of Higher Education of the Russian Federation develops educational standards for all university majors to unify academic requirements and conditions. This document is available for everybody; thus, students and universities are aware of general requirements. Moreover, a syllabus for each subject is designed in accordance with the standard.

\subsection{Questionnaire}

To reveal the students' attitude towards learning English a questionnaire "English in my life" has been designed. It can be regarded as Present Situation Analysis as its aim is to investigate students' strengths and weaknesses [28]. The questions are given in Table 1.

Table 1. "English in my life" questionnaire for students.

\begin{tabular}{|l|l|l|}
\hline \multicolumn{2}{|l|}{ English in my life } & \\
\hline 1 & How often do you use English? & \\
\hline 2 & When and where do you need English? & $\begin{array}{l}\text { Which language activities (reading, writing, listening, speaking) should be paid special } \\
\text { attention in English lessons? Why? }\end{array}$ \\
\hline 4 & $\begin{array}{l}\text { Rate English 1-10 among other subjects you have at University, 1 being least important } \\
\text { and 10 most important. }\end{array}$ & $\begin{array}{l}\text { Which category would you place English to - General Knowledge Subjects or Special } \\
\text { Subjects? Or both? Why? }\end{array}$ \\
\hline 6 & $\begin{array}{l}\text { Which language activity (-ies) (reading, writing, listening, speaking) is the most } \\
\text { difficult for you? }\end{array}$ & \\
\hline 7 & Do you think a good command of English will improve your career prospects? & \\
\hline
\end{tabular}

The questionnaire analysis shows that most students do not use English very often. Apart from English lessons, they need it for travelling, occasional watching of films and series, and reading some interesting books or articles that have not been translated into Russian. The majority of students do not see any prospects of using English in their profession although they admit the important part English plays nowadays. It may be linked to a traditional image of higher education and a well-educated person. Most students agree that speaking and listening skills should be given priority while the same skills are named to be the most difficult.

To draw a clearer picture of the English language skills engineering students may need in the future a survey was carried out which involved $\mathrm{PhD}$ students, engineers and academicians. A number of tools were used - questionnaires, interviews, observations to gather as much information as possible. The information is of great interest not only for English lecturers, but also for students as it provides an insight into their professional area. Therefore, it can be considered as a part of Target Situation Analysis [15, 29]. 
A total of 65 engineers, research fellows and academicians were asked a number of questions entitled "English in my job". The questions asked to the researchers are given in Table 2.

Table 2. "English in my job" questionnaire for academics.

\begin{tabular}{|c|l|l|}
\hline \multicolumn{2}{|l|}{ English in my job } & \\
\hline 1 & Do you need English in your job? & \\
\hline 2 & $\begin{array}{l}\text { Which situations listed below are relevant to your experience of using English? (tick } \\
\text { the appropriate) }\end{array}$ & \\
\hline & a. oral communication with foreign peers (everyday topics / professional topics) & \\
\hline & b. written communication (emails, applications, etc.) & \\
\hline & c. writing scientific articles & \\
\hline & d. preparation and delivery of presentations in conferences, etc. & \\
\hline & e. reading literature & \\
\hline 3 & f. other (what?) & How often do you communicate with foreign counterparts? \\
\hline 4 & $\begin{array}{l}\text { Which language activity (-ies) (reading, writing, listening, speaking) is the most } \\
\text { difficult for you? }\end{array}$ & \\
\hline
\end{tabular}

The analysis of the obtained results showed that English is mostly used for discussions of various topics, professional and non-professional alike, presenting results of research in the written form (articles) and orally (presentations). Thus, the survey revealed that the most popular ways of communication among those surveyed are oral communication on every day and professional topics, writing articles and preparation and delivery of presentation. Speaking and listening were found to be the most challenging language activities.

The results show that the English course for engineering students should be focused on the development of all language activities - reading, writing, speaking and listening. However, due to insufficient length of the course it is impossible to spare enough time for all language activities. One of the possible solutions can be an emphasis on the research activity and making a presentation as a result of it. This technology can be regarded as a practical application of a Task-based learning.

\subsection{Interview}

The students were asked about their English learning background, learning strategies they have used, their weaknesses and strengths, suggestions (if any) on course design. They were also asked about their expectations from the course. All students' answers and ideas were carefully considered and taken into account which resulted in a better tailored course. Moreover, the students felt the importance of their thoughts and ideas. It created a comfortable environment of trust and respect. Apart from that, they felt more responsibility for their academic achievement as they saw that tutors did their share thoroughly.

\subsection{Placement test}

To get information about the current level of English a placement test has been used. It contained 120 questions where grammar, lexis and basic communication as well as intercultural skills were assessed. The level of questions ranged from A1 to C1. Some examples are as follows: 


\begin{tabular}{|c|c|c|c|}
\hline \multicolumn{2}{|c|}{ Instead of staying in a hotel, we booked a } & \multicolumn{2}{|l|}{ partment. } \\
\hline do-it- & B survival & C self-study & D self-catering \\
\hline yourself & & & \\
\hline \multicolumn{4}{|l|}{ I'm always interested in } \\
\hline A try & $\mathrm{B}$ tries & $\mathrm{C}$ tried & $\mathrm{D}$ trying \\
\hline \multicolumn{4}{|c|}{ Look, there's absolutely no need in ___ What's done is done, you just have to get on with } \\
\hline \multirow{2}{*}{$\begin{array}{l}\text { A as cool as a } \\
\text { cucumber }\end{array}$} & B crying over & \multirow[t]{2}{*}{ C full of beans } & D my bread and \\
\hline & spilt milk & & butter \\
\hline
\end{tabular}

Fig. 1. The level of questions ranged from $\mathrm{A} 1$ to $\mathrm{C} 1$.

The survey confirmed the idea that effective professional intercultural communication is based on the well-developed specific language competence and intercultural competence [30, 31]. A course of English at a technical university should therefore combine an English for Specific Purpose course and Intercultural Communication training. This is the way to make the English course more motivating, relevant and enjoyable for engineering students. Unfortunately, low motivation to learn a foreign language is still an issue at technical universities. There are a number of reasons for that. Firstly, first-year students are focused on their major and special subjects that are new for them and take up most of students' time. Secondly, many students are not aware of the fact that English may help them develop their professional skills and serve as a tool to increase their professional competence. They believe that English belongs to 'general knowledge' subjects that will have vanished by the third year being irrelevant for the future profession. Thirdly, freshmen have to adapt to the new learning environment and requirements and often do not cope with all the changes they are faced with. They may feel confused and not able to see all opportunities they have.

\subsection{Experiment}

\subsubsection{Preparation}

To bring the requirements to life which are stated in the educational standard and expressed by industrial companies, it is necessary to set a clear goal, develop a plan of its achievement, stick to it and do the best to implement the plan. It is essential for students to be active learners, i.e. to be aware of the process, their achievements and failures, to find most suitable learning strategies. As Task-based learning serves the goal, it was chosen as a leading teaching method. It aims at improving accuracy, complexity and fluency in order to develop learners' communicative competence [32].

The experiment was based on the interdisciplinary approach where English and students' major merged. The goal was to make English acquisition more effective. It was also important to show the students that English can be an efficient tool for developing professional skills.

A tailored ESP module was adjusted to the revealed needs. In the course design special attention was paid to the selection of teaching materials as they have to meet a number of requirements. First of all, they should correspond with the English level of students. Secondly, materials should be of professional and/or personal interest for students to motivate them. Thirdly, they should contribute to developing intercultural and professional competence. The experience of using English by $\mathrm{PhD}$ students and academic staff was also taken into consideration. 


\subsubsection{Description}

The designed module has three connected parts which go alongside and taught simultaneously. The structure of the module is given in Table 3.

Table 3. Structure of ESP module.

\begin{tabular}{|l|l|l|l|}
\hline Part & \multicolumn{1}{|c|}{ Title } & \multicolumn{1}{c|}{ Task/Goal } & \multicolumn{1}{c|}{ Activities } \\
\hline 1 & $\begin{array}{l}\text { 30-day } \\
\text { challenge } \\
\text { "Best } \\
\text { practices in } \\
\text { my major" }\end{array}$ & $\begin{array}{l}\text { Collect data on achievements, } \\
\text { discoveries, challenges in the field of } \\
\text { study }\end{array}$ & $\begin{array}{l}\text { Reading professional literature } \\
\text { in English, preparation and } \\
\text { delivery short reports, } \\
\text { discussion }\end{array}$ \\
\hline 2 & $\begin{array}{l}\text { ESP teaching } \\
\text { materials }\end{array}$ & $\begin{array}{l}\text { Improve English level, increase } \\
\text { awareness of traditional and } \\
\text { company cultures }\end{array}$ & $\begin{array}{l}\text { Vocabulary and grammar } \\
\text { exercises, communicative tasks }\end{array}$ \\
\hline 3 & Presentation & $\begin{array}{l}\text { Prepare and deliver a presentation } \\
\text { reporting results of 30-day challenge }\end{array}$ & $\begin{array}{l}\text { Speech writing, making slides, } \\
\text { presentation delivery and } \\
\text { discussion }\end{array}$ \\
\hline
\end{tabular}

The first part was a challenge. 85 second-year students studying agricultural and environmental engineering were offered to take up a 30-day challenge. The task for students was to carry out research in their major. The goal was to learn the world's best practices and experience in their major every day, keep track of their findings and prepare a presentation on their achievements. For their research students read literature in English to get familiar with experience and best practices applied across the world [33]. The students were free to choose the topic for their presentation. Every week the students delivered a brief report on their progress. It turned out to be an effective tool in encouraging and motivating group mates as the topics were relevant and of great interest to everyone. Giving their reports the students felt more free than usual as they were talking about important for their future things. At that moment they were focused on their major, they were not afraid of making a mistake. After each report there was a short discussion. However, English improved significantly in 30 days as all speech parts were actively involved - reading and writing were mostly used for preparing a report, speaking and listening were developed while delivering reports and having discussions.

The second part of the module consisted of teaching materials carefully selected after the analysis of the students' needs. They included traditional grammar and vocabulary exercises based on the lexical approach, communicative tasks, work with video materials. Traditionally, task design is usually strongly by the nature of the selected text itself and the discourse features present which can be 'noticed' by learners [34]. The materials, therefore, contained texts about leading companies, their background, commitments, way to success, present day operations and future projects. An emphasis was made on the culture of the countries where the companies started and company cultures. For example, information from official web-sites was compared and contrasted, students identified professional and cultural similarities and differences between the companies. The content of the designed module included the following chapters:

- company culture;

- meeting new people;

- corporate culture clashes;

- history of agricultural and environmental engineering;

- current trends in agricultural and environmental engineering.

The third part was aimed at preparing a presentation highlighting the results of the 30 day challenge. To reach the goal it was important to improve presentation skills. For that purpose, we watched some really good examples - they were TED talks. We analysed the 
slides, speech, body language of the speakers. Students identified the strong points they could use in their own presentations. The length of the presentation was limited to 10 minutes. Every student managed to prepare and deliver their presentation. Each presentation was followed by discussion. We tried to simulate real international conference environment.

\section{Results}

The requirements to the level of English given in professional and academic standards of a certain major are important to know as they help set a general target for the course. Having studied the requirements of various companies we found out that they are looking for graduates whose level of English is at least Upper-Intermediate even if the job is located in Russia. This information is quite important for students as they know that English increases their competitiveness in the labour market. As a result, the motivation to learn English increases, too.

The academic standard for agricultural and environmental engineering major provides communicative competence in a foreign language as one of the key competencies saying that the curriculum must aim at developing skills of oral and written business communication in mother tongue and a foreign language. The standard also includes intercultural competence as an ability to perceive cultural diversity in various contexts.

The analysis of students' answers (see questions in Table 1) showed that English is not regarded to be part of professional knowledge or skills though students admit the significant role English plays today. As students do not see any prospects of English in professional use, their motivation to learn it is low.

The answers of engineering professionals who answered a number of questions (see Table 2) revealed that the most popular situation where they used English are oral communication with foreign counterparts on professional and everyday topics using technical and general English (90\%), writing research articles (80\%), participation in conferences, seminars, etc. (75\%). The most difficult activity turned out to be speaking (70\%), whilst it is the most popular activity in professional communication.

The needs analysis provided a rationale for designing an ESP module that combines general and professional English. It focuses on developing speaking skills. Moreover, it is aimed at increasing students' awareness of the role English plays in cultural and professional areas of modern society to increase their motivation.

The designed module has three distinctive purposes:

- to stimulate students to use English more often, especially for research activities;

- to increase their English level and intercultural awareness;

- to improve presentation skills.

In the feedback students admitted that the module had been intense and more demanding than a usual course. But they were happy to have an opportunity to advance not only in English, but also in their research work. They felt that they were learning English not just to know it better and show it in English classes. They discovered new ways of application of the English language, that is to make progress in their major, to improve presentation skills, to increase intercultural awareness.

We studied students' motivation before and after the experiment (see Figure 1). The prevailing motivation type remained the same which is an intermediate type combining the features of intrinsic positive and external negative motivation. However, the number of students with intrinsic positive motivation increased. It means that students realized opportunities and benefits English offers for their future career. 


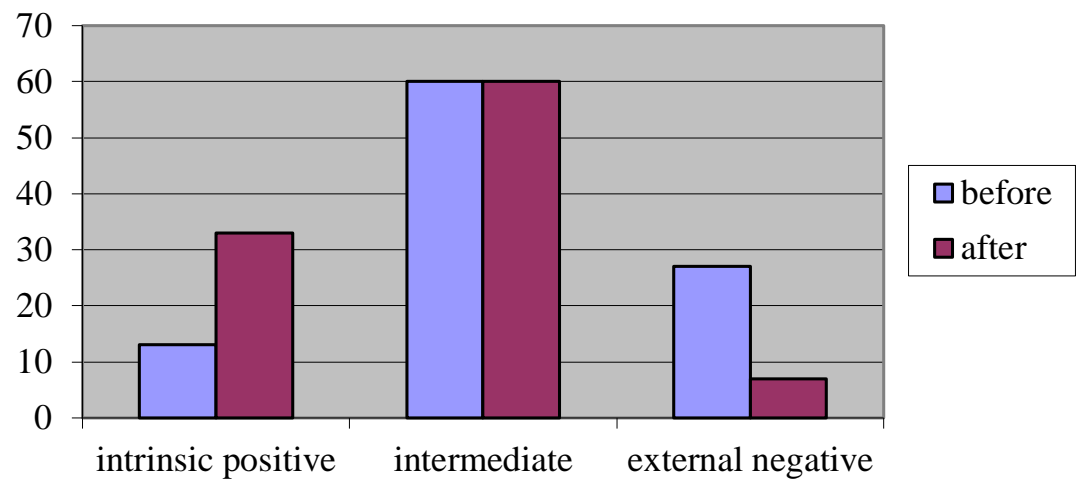

Fig. 2. Motivation types of students before and after experiment.

The goals of the module were quite ambitious, but the experiment proved it to be successful. In our opinion, the key is in clear goal setting, thorough module design, close cooperation between tutor and students, and shared responsibility for the results. Individual work and free choice of the presentation topic contributed into responsibility growth and motivation improvement.

To sum up the obtained results, it should be highlighted that the needs of engineering students are not confined by their present expectations. Numerous researches discussed in Methods section show that a combination of needs should be taken into consideration - those of students and professionals. This integrated approach resulted in reaching the goals set.

\section{Discussion}

The carried out needs analysis and the developed module provided a lot of food for thought. First of all, we were surprised how enthusiastic the students were, especially at the beginning of the experiment. Of course, not all of them managed to maintain high motivation but we could see that their progress had been faster than usual, attendance rate had been higher. Students liked the idea of revealing their needs, they were interested in having something new, to change a routine. They really appreciated new opportunities discovered in English classes. Sharing their thoughts about the experience they gained, students claimed that they liked communication and discussions best of all. It must have been due to their age (17-19) and psychological features. They like being exposed to new experience, challenges. Thus, this is one of the ways how to increase their intrinsic motivation. It is beneficial for both, students and tutors, when students think less about credit points and more about what they can share with their peers in English and how they can get more successful $n$ their field.

In the feedback students said that they did feel individual approach which was very important. They learnt the material with interest. It should be noted that the attendance rate increased significantly. It was beneficial for both, the students and the tutor. Students did not have to catch up, the tutor did not have to explain again. Moreover, students admitted that the level and content of the materials met their needs and expectations. That is why they did not want to miss lessons. They felt more wish and responsibility rather than obligation and it was a key factor in successful learning. 


\section{Conclusions}

Teaching English for specific purposes used to rely mainly on reading texts and learning terms. Now there are a lot of tools that make learning more diverse, enjoyable and efficient. They allow English tutors to tailor the course in accordance with the learners' needs. Needs analysis is essential in creating such an English course. To be an effective tool needs analysis must embrace a number of activities - study of educational standards (if any), questionnaire, interview, placement test. In case of designing an ESP module it is of practical value to carry out a survey among professionals working in the certain field. It should be noted that it is the quality of the human capital of universities that is of decisive importance for the realization of all innovations in the system of higher education [35] and modern approaches implemented in various fields [36].

For the module design an interdisciplinary approach and task-based learning were used for a number of reasons. Firstly, English and students' major merged. Secondly, materials were of professional and personal interest of students. It motivated them as they could see a connection with their future job. Thirdly, a wide range of materials contributed to developing intercultural and professional competence. Finally, materials corresponded with the English level of students.

An important part of the module was a development of presentation skills. These skills are traditionally not the strongest ones of engineering students. Thus, it was a challenge for them to prepare and make a proper presentation. But the feedback showed that the students appreciated it a lot as presentation delivery is regarded one of the important skills for a modern engineer.

The described complex approach combining interdisciplinary approach and task-based learning proved to be effective in teaching engineering students and improving their motivation. The combination of various approaches is likely to be widely accepted and implemented these days and in the near future due to rapid changes in industries and politics around the globe.

\section{References}

1. C.S.C. Chan, English for Specific Purposes 56, 68-83 (2019)https://doi.org/10.1016/j.esp.2019.07.003

2. L.P. Yatsevich, Modern Sciences and Education 12(13) (2016) https://www.iupr.ru/sovremennye_nauki_i_obrazovanie_12_13_2016/

3. S. Salameh, Journal of Education and Training 4(1), 55-68 (2017)

4. E. Tarone, G. Yule, Focus on the Learner (Oxford University Press, Oxford, 1989)

5. T. Hutchinson, A. Waters, English for Specific Purposes: A Learning Centered Approach (Cambridge University Press, New York, 1986)

6. H.G. Widdowson, Learning Purpose and Language Use (Oxford University Press, Oxford, 1983)

7. J. Grunert, B. Millis, M. Cohen, The course syllabus: a learning-centered approach (Jossey-Bass, 2007)

8. Y.S. Ng, J. Chuah, Langlit.org 2(2), 29-40 (2015) https://www.researchgate.net/publication/306100054_needs_analysis_of_english_for_t echnicians_a_case_study

9. J.D. Brown, The elements of language curriculum: A systematic approach to program development (Heinle and Heinle, Boston, 1995)

10. F. Chambers, ESP Journal 1(1), 25-33 (1980) 
11. T. Dudley-Evans, M.J. St John, Developments in English for specific purposes (Cambridge University Press, Cambridge, 1998)

12. M. Ellis, C. Johnson, Teaching business English (Oxford University Press, Oxford, 1994)

13. R.R. Jordan, English for academic purposes: A guide and resources book for teachers (Cambridge University Press, London (UK), 1997)

14. E. Gözüyeşil, Procedia - Social and Behavioral Sciences 116, 4182 - 4186 (2014) DOI: 10.1016/j.sbspro.2014.01.91

15. www.researchgate.net/publication/275543442_An_Analysis_of_Engineering_Students' _English_Language_Needs

16. R. West, Needs analysis in language teaching. Language teaching 27(1), 1-19 (1994)

17. E.D. Lesiak-Bielawska, English for Specific Purposes World 48(16), 1-23 (2015) http://www.esp-world.info/Articles_48/Lesiak_Bielawska_E.pdf

18. M. Asmali, Teaching English with Technology 18(3), 86-104 (2015) https://www.tewtjournal.org/issues/volume-18/volume-18-issue-3/

19. H. Malström, D. Pecorari, Ph. Shaw, English for Specific Purposes 50, 28-39 (2018) https://doi.org/10.1016/j.esp.2017.11.002

20. G. Detlev, E. Jansen, World Transactions on Engineering and Technology Education 1(1) (2002)

21. L.A. Lee, Soc. Sci. 6, 26 (2017)

22. I. Gerasimova, G. Shamsutdinova, METOO movement and its influence on culture of some countries. Current issues of philology and translation (Cheboksary, Russia, 2018) https://elibrary.ru/item.asp?id=36753354

23. K. Vachuska, J. Brudvig, Soc. $\quad$ Sci. $7(2), \quad 21 \quad$ (2018) https://doi.org/10.3390/socsci7020021

24. M.R. Garcia, P.F. Silva, Teaching English with Technology 18(2), 69-92 (2018) https://www.tewtjournal.org/issues/volume-18/volume-18-issue-2/

25. E. Sapir, Language: an introduction to the study of speech (Harcourt, Brace, 1 New York, 1921)

26. A.K. Belousova, N.K. Epritskaya, Integration of Education 22(4), 750-765 (2018) DOI: 10.15507/1991-9468.093.022.201804.750-765

27. E.A. Makarova, Integration of Educatio 22(3), 551-568 (2018) DOI: 10.15507/19919468.092.022.201803.551-568

28. Y.L. Lu, English for Specific Purposes 50, 116-129 (2018)

29. P. Robinson, ESP today: A practitioner's guide (Prentice Hall, New York, 1991)

30. J. Munby, Communicative syllabus design: A sociolinguistic model for defining the content of purpose-specific language programmes (Cambridge University Press, London, 1978)

31. I. Gerasimova, The teaching potential of borrowings in English lessons (SaintPetersburg Mining University, St.-Petersburg, 2017) https://elibrary.ru/item.asp?id=32716117

32. J.M. Sishchuk, I.G. Gerasimova, M.V. Goncharova, Anthropocentric world picture in German and English geological and mining metaphoric terms. Innovation-Based Development of the Mineral Resources Sector: Challenges and Prospects - 11th conference of the Russian-German Raw Materials (2018) https://www.scopus.com/record/display.uri?eid=2-s2.0- 
85056789221\&origin=resultslist\&sort=plf-

$\mathrm{f} \& \mathrm{src}=\mathrm{s} \& \mathrm{sid}=\mathrm{f} 9 \mathrm{c} 80 \mathrm{~b} 99 \mathrm{f} 91802640 \mathrm{e} 5 \mathrm{fa} 82396 \mathrm{c} 7957 \mathrm{f} \& \mathrm{sot}=\mathrm{aut} \& \mathrm{sdt}=\mathrm{a} \& \mathrm{sl}=18 \& \mathrm{~s}=\mathrm{AU}-$

ID\%2857205335882\%29\&relpos=1\&citeCnt=1\&searchTerm $=($ Retrieved 04.02.2020 $)$

33. B. Waluyo, Electronic Journal of Foreign Language Teaching 16(1), 153-168 (2019) http://e-flt.nus.edu.sg/v16n12019/waluyo.pdf

34. A.A. Lapinskas, Journal of Mining Institute 233, 561-570 (2018) DOI: 10.31897/PMI.2018.5.561

35. A. Gilmore, N. Millar, English for Specific Purposes 51, 1-17 (2018) https://doi.org/10.1016/j.esp.2018.02.002

36. I.A. Alekseeva, M.G. Gildingersh, Journal of Mining Institute 232, 421-427 (2018) DOI: 10.31897/PMI.2018.4.421

37. V.I. Grigoriev, A.B. Makhovikov, S.A. Sidorenko, Teoriya i Praktika Fizicheskoy Kultury 2019(3), 17-19 (2019) 